\title{
CENTROS DE INTEGRAÇÃO DA CIDADANIA democratização do sistema de justiça ou o controle da periferia?
}

\author{
Eneida Gonçalves de Macedo Haddad \\ JACQUeline SinhoretTo
}

\begin{abstract}
Resumo: A política de implantação dos Centros de Integração da Cidadania - CICs, idealizada com o objetivo de levar justiça e segurança a segmentos da população desprovidos desses direitos, passou a integrar as propostas de reforma do sistema de justiça. Alargando o conceito de direito à justiça, essa política aponta para a possibilidade de aperfeiçoamento da democracia e da cidadania.

Palavras-chave: políticas públicas; segurança; cidadania; sistema de justiça.

Abstract: The establishment of Centers of Citizen Integration (CIC), conceived to bring justice and safety to underserved segments of the public, became a vehicle for judicial reform. Expanding the concept of the right to judicial access, this policy seems to contain the possibility of a strengthening of democracy and citizen participation.
\end{abstract}

Key words: public policies; safety; citizenship; judicial system.

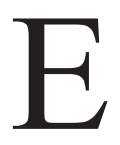

ste artigo refere-se a algumas reflexões sobre os resultados apontados por uma pesquisa realizada pelo Núcleo de Pesquisas do Instituto Brasileiro de Ciências Criminais - Ibccrim ${ }^{1}$ sobre os quatro Centros de Integração da Cidadania - CICs, existentes na cidade de São Paulo até novembro de 2001, data em que foi iniciado o trabalho de campo. ${ }^{2}$ A partir do término da mesma, em dezembro de 2002, tem-se procurado ampliar o debate sobre essa política pública, considerando o fato de que a experiência de São Paulo nas zonas Norte, Sul, Leste e Oeste suscitou a criação de CICs em diversos estados do território nacional.

A implantação desses centros corresponde a uma política pública idealizada com o objetivo de levar justiça e segurança a segmentos da população paulista desprovidos desses direitos, no esteio da democratização das instituições públicas que marcava o início dos anos 90 . Não obstante, o período é também marcado pela problematização do crime e da violência na vida nacional, exigindo do Estado soluções e respostas ao crescente sentimento de insegurança manifestado em todas as camadas sociais.

Em face da proposta de abordar a trajetória dos CICs, encontra-se uma realidade histórica marcada por uma complexa teia de desafios no tocante a contradições, associações, oposições, colonizações, interpenetrações dos discursos da democratização e do controle social. Nesse contexto, os resultados dessa política pública podem, no limite, vir a negar os objetivos defendidos em sua proposta inicial.

\section{O QUE SÃO OS CENTROS DE INTEGRAÇÃO DA CIDADANIA}

O CIC teve início como uma ação da Secretaria de Justiça e Defesa da Cidadania do Estado de São Paulo em 1996. Tornou-se, em 2001, uma coordenadoria regulamentada pelo decreto estadual 46.000 , onde estão arrolados os seus princípios norteadores: a prevenção de conflitos interpessoais ou de grupos; a implementação de alternativas comunitárias de prevenção e solução de conflitos; a participação de associações e movimentos populares no planejamento, na execução e na avaliação das ações desempenhadas; a localização em regiões carentes e com pouca oferta de serviços públicos; a qualidade na prestação de serviços conforme o Código de Defesa do Usuário de Serviços Públicos do Estado de São Paulo; a integra- 
ção e a colaboração entre os órgãos e entidades estatais para a prestação de serviços; a desconcentração do atendimento ao cidadão; a aproximação do Estado e da comunidade; o estímulo à organização popular.

A articulação da parceria entre diversas secretarias de Estado, o Poder Judiciário e o Ministério Público, ocorre através de convênios com a Secretaria de Justiça, responsável por gerenciar o projeto, capacitar os parceiros para o trabalho integrado, relacionar-se com a comunidade local e fornecer alguns recursos materiais. A proposta de descentralização do atendimento no espaço da cidade realiza-se mediante a concentração de múltiplos órgãos públicos no mesmo edifício.

Serviços de identificação, posto da Polícia Militar, atendimento da Polícia Civil, atendimento de assistência social, balcão de empregos, Procon, além dos parceiros anteriormente mencionados, integram o programa CIC. Em sua concepção, o projeto contempla a possibilidade de outras parcerias a fim de atender a demandas específicas de cada localidade em que se instala. Assim, tem-se conhecimento de unidades planejadas em que Conselhos Tutelares, Febem, ou órgãos municipais integram-se ao CIC. Além disso, o espaço costuma ser aproveitado pelas associações civis para reuniões, eventos, cursos e outras atividades comunitárias.

A pesquisa $^{3}$ aqui relatada privilegiou a observação da prestação dos serviços que contemplam as demandas por acesso a justiça e segurança pública. Isto se justifica em razão do projeto ter sido proposto, pela primeira vez, como uma política voltada para a ampliação desse acesso, por um grupo de penalistas engajados na elaboração do programa de governo de um candidato ao governo de São Paulo. ${ }^{4}$

\section{NOTAS SOBRE A TRAJETÓRIA DO CIC}

Os idealizadores do projeto eram defensores do garantismo ${ }^{5}$ e da transformação do modelo de justiça vigente, no início dos anos 80 , destacando-se dentre eles alguns desembargadores de Justiça que tiveram uma atuação diferenciada na Quinta Câmara do Tribunal de Alçada Criminal de São Paulo - Tacrim.

O grupo identificava-se com movimentos de crítica ao autoritarismo estatal ou social, tendo os direitos humanos como princípio de pensamento e ação. No fim da ditadura, esse discurso vinculava-se às garantias de defesa dos perseguidos pela repressão, fossem presos comuns ou políticos. Assim, a identificação com o garantismo colocava o grupo na luta por democracia e justiça social, des- toando do conservadorismo dos tribunais e politizando a atividade jurisdicional.

Após a promulgação da Constituição Federal de 1988, várias teses jurídicas defendidas pelo grupo tornaram-se majoritárias. Todavia, sua crítica não se limitava ao ordenamento jurídico oficial, objetivando transformar também a prática da justiça.

Ao se resgatar a história da criação do projeto dos CICs, constatou-se em sua gênese o compromisso com a transformação política do sistema de justiça, das relações de poder entre as instituições e os cidadãos. Por isso, ao recontar para os pesquisadores a história do projeto, seus idealizadores falaram em um novo pacto social, em um novo paradigma de justiça e mesmo em revolução.

Nesse cenário, o funcionamento do CIC exigiu das instituições e dos profissionais duas inversões de prioridade: a adequação de todos os serviços públicos à realidade dos conflitos (e não o contrário) e o deslocamento das autoridades no espaço da cidade.

Entretanto, o CIC não pode ser tomado como um projeto acabado. Sua implementação depende da interação contínua entre planejadores, executores e usuários, para constantemente atender às demandas plurais de justiça e segurança. Além disso, seus objetivos reclamam que seja sempre reatualizado por novas demandas, pressupondo o diálogo entre os envolvidos para a ampliação sem fim da consciência de direitos e papéis.

O principal elemento definidor do CIC é a proposta de integração entre os serviços em si e destes com a comunidade. Há uma nova forma de prestar serviços públicos, não mais fragmentadamente, mas integrando as políticas de segurança, justiça, assistência social, emprego, etc. Há ainda a aposta em um Estado não mais identificado com a repressão, mas aberto à participação da comunidade na gestão do equipamento e na resolução dos problemas coletivos.

Diante da "ausência" do Estado nas periferias, o equipamento deve, segundo o projeto, simbolizar a ocupação do "vazio", mediante oferta de serviços de segurança e justiça em áreas carentes desses equipamentos. A implementação disso exige uma reforma do Estado fundada na descentralização dos serviços. Assim idealizados, esses centros, teoricamente, deverão romper com o tradicionalmente oferecido: autoritarismo, centralização, corporativismo e fragmentação. Ocorre que, para efetivar-se a integração entre a comunidade local e os agentes estatais, é necessário abandonar a ideologia de "ocupação do vazio", o que significa propor-se a um trabalho 
efetivamente conjunto entre os representantes do poder público e os cidadãos no diagnóstico de problemas, na definição de prioridades, na gestão dos recursos, nos rumos da política de acesso à justiça e na avaliação do serviço prestado.

A pesquisa apontou a complexidade e a ambição desse projeto. Além da descentralização dos órgãos da justiça e da segurança, do atendimento eficaz às demandas concretas da população, a proposta avançava na reflexão da necessidade de serem criados arranjos institucionais capazes de desenvolver uma nova cultura jurídica comprometida com a redução das injustiças sociais, em que aplicação da justiça seja equivalente a justiça social.

Essa nova cultura, sem lugar para a repressão penal, pode ser lida como incapaz de enfrentar o fenômeno conhecido por "o crescimento da violência urbana". Este constitui-se num dos riscos para a implementação do projeto: o deslocamento do discurso da transformação para o discurso da repressão ao crime.

Conforme se tem constatado, há possibilidade de a prestação de serviços acabar por se inserir numa lógica de prevenção do crime, ou - o que é menos desejável - de combate ao crime. Nessa lógica, subordina-se toda e qualquer ação pública à avaliação de sua eficácia em prevenir e combater o crime. A educação ou a justiça passam a ser justificadas, não como direitos fundamentais, mas como estratégias de controle do crime.

É o risco ao qual, segundo as análises empreendidas no decorrer da pesquisa, o projeto foi exposto ao ser incorporado, em 2000, pelo governo federal, entre as ações de prevenção da violência do Plano Nacional de Segurança Pública. Isto porque a gestão dessas ações, não tendo ficado sob a competência do Ministério da Justiça (como o restante do Plano), transferiu-se ao Gabinete de Segurança Institucional, órgão ligado à Presidência da República, cujos cargos são privativos de oficiais das Forças Armadas. A partir daquele momento, a gestão do CIC passou a fazer parte do Plano de Integração e Acompanhamento dos Programas Sociais de Prevenção da Violência - Piaps, que articulava programas e políticas federais, estaduais e municipais com impacto na prevenção da violência. Assim, de uma proposta inovadora de transformação da relação entre o Estado e os cidadãos na garantia dos direitos, o CIC converteu-se, num primeiro momento, numa ação de segurança pública, correndo já aí o risco da redução da experiência. Todavia, no contexto de colonização das questões de segurança pública pela ideologia da segurança nacional durante a segunda gestão de
Fernando Henrique Cardoso, ${ }^{6}$ os fundamentos filosóficos dos CICs acabaram desvirtuados, na medida em que passaram a servir à estratégia da repressão.

Ainda que a gestão do CIC não estivesse sob a coordenação do Ministério da Justiça, a aprovação de projetos visava a utilização dos recursos do Fundo Nacional de Segurança Pública, administrado pela Secretaria Nacional de Segurança Pública - Senasp.

Com a mudança de governo em 2003 - e a extinção do Piaps - as decisões voltaram à esfera do Ministério da Justiça, que prontamente passou a reunir informações sobre a avaliação do programa em São Paulo. Observe-se que a proposta de ampliação dos CICs insere-se, no discurso do novo ministério, no projeto da reforma do sistema de justiça, constituindo, até o presente, uma das prioridades da recentemente criada Secretaria de Reforma do Judiciário.

Os novos gestores de Brasília estão preocupados em dar efetividade aos princípios de política pública idealizados no passado, reatualizando-os no presente como um experimento de prática inovadora em administração da justiça. Desta forma, não buscam reproduzir os passos dados pelo governo de São Paulo na criação das unidades já em funcionamento, enunciando até mesmo reservadas críticas à condução do programa paulista.

\section{O CIC E A REFORMA DA JUSTIÇA}

Costuma-se associar o conhecimento obtido pela pesquisa empírica ao processo de limpeza, de retirada de camadas. Entretanto, a compreensão da realidade alcançada com a investigação acerca dos centros de integração da cidadania assemelhava-se à dinâmica das partículas de poeira. Quanto mais os fatos acumulavam-se, superpunham-se, mais visíveis eles se tornavam e, com isso, a promessa de se obter resposta à indagação que conduzia os pesquisadores: afinal, qual é a novidade deste equipamento instalado na periferia das zonas norte, sul, leste e oeste da cidade?

Se ao longo do levantamento empírico apreendiam-se algumas transformações na cultura jurídica necessárias para que o projeto CIC vingasse, com a análise e interpretação dos resultados ficaram evidentes três rupturas que poderão viabilizar a superação do modo tradicional de funcionamento do sistema de justiça:

- ruptura com a fragmentação entre os campos de saber do direito, e os modos de intervenção típicos de cada um deles; 
- ruptura com a fragmentação entre os diversos órgãos públicos e setores do Estado responsáveis pela garantia dos direitos fundamentais de cidadania;

- ruptura com a segmentação entre o Estado e a sociedade civil nos assuntos públicos.

As três significam possibilidades de superação do modo fragmentado como o Estado brasileiro vem administrando conflitos ao longo da história. Todavia, não se pode desconsiderar jamais o fato de que essas rupturas não estão presentes de modo uniforme em todos os momentos, em todos os serviços ou em todas as unidades do CIC em funcionamento.

Mesmo para fins didáticos, não é possível abordar essas promessas (ou rupturas) separadamente, uma vez que isso levaria à fragmentação da análise ou, em outras palavras, ao esquecimento da dialética existente entre elas. Se não, vejamos.

O aparelho de Estado está assentado em uma lógica em que a defesa da independência entre as diversas instituições que o compõem não deve ameaçar sua unidade, da qual depende a eficácia necessária à sua funcionalidade. A divisão do trabalho, marca de cada instituição, leva a uma outra sorte de fragmentações cuja apreensão é fundamental para que se descortine, no que interessa neste texto, o funcionamento do sistema de justiça. Assim, diversas instituições são responsáveis pelo exercício do controle social, mas não necessariamente trabalham articuladas entre si, o que faz com que as propostas de incremento da eficácia no controle da violência encontrem inúmeras resistências na sua implementação. Essa disfuncionalidade busca ser superada por aquilo que, no CIC, denomina-se integração. Se o CIC se limitar a trabalhar com o objetivo do aumento da eficácia dos órgãos públicos, não realizará suas potencialidades transformadoras, mas aumentará a extensão do poder estatal no controle das relações sociais.

Entretanto, a proposta do trabalho integrado não reproduz a organização típica das instituições porque questiona a hierarquia entre os agentes públicos, na medida em que co-responsabiliza todos os parceiros, não apenas pelo atendimento às demandas ingressantes, mas pela própria gestão do equipamento e da política pública. Logo, dentro de um CIC, a orientação jurídica e a educação em direitos deve ser tarefa de todos, do escrevente ao juiz. O questionamento da hierarquia significa o questionamento do saber próprio de cada corporação. O desafio do CIC para a democratização das instituições é não se perder na disputa de saberes entre as corporações ou na resistência ao abandono da hierarquia. É assim que, na prática, podem ser encontrados juízes disputando a liderança do programa com os gestores administrativos e tentando reproduzir no CIC o ambiente forense, incluindo nisso o uso de togas, as relações formais e a centralidade do juiz como diretor da unidade.

O questionamento dos saberes fragmentados dos agentes públicos também se revela na proposição de um outro modo de administração dos conflitos, qual seja, o que se convencionou chamar de metodologia da mediação, na qual o agente estatal não define a situação nem o modo de resolvê-la, mas serve como facilitador da negociação de uma solução entre as partes. Para isso, ele precisa superar a divisão clássica entre Direito Civil, Direito Criminal, Direito Trabalhista, não se restringindo nos conhecimentos técnicos inerentes a esses campos.

É justamente nessa aparente indefinição de critérios (ou de fundamentos de aplicação do direito) que se encontra um outro ponto de inflexão na trajetória do CIC. Se reduzir-se a um equipamento no interior do Estado em que se pratica a mediação descolada da garantia dos direitos fundamentais, ele se limitará a ratificar acordos privados que podem significar a violação dos direitos humanos. Mas o projeto do CIC propõe a superação da fragmentação dos saberes com a produção alternativa do direito no sentido de atender à indivisibilidade dos direitos humanos, sem lugar na estrutura formal da justiça, que separa os interesses públicos em bens jurídicos cuja proteção torna-se contraditória: liberdade versus segurança, propriedade versus direito.

É assim que, no CIC, se pode presenciar intervenções de autoridades públicas em conflitos interpessoais motivados pelo uso ilegal do solo para moradia, ou na regulação de situações de convivência em grandes conjuntos habitacionais. Nesse aspecto, a informalização abre espaço para que a administração da justiça signifique justiça social, na medida em que torna efetivos os direitos sociais assegurados no ordenamento jurídico.

$\mathrm{Na}$ medida em que a mediação se mantiver pautada nas demandas dos movimentos sociais com expressão local, não há o risco de empobrecer a qualidade da oferta de serviços de justiça destinados aos moradores da periferia. É aí que as três rupturas se completam. O CIC não consiste em uma transformação interna ao Estado, mas representa um questionamento das fronteiras que separam o cidadão comum das decisões políticas que o afetam. Acrescente-se ainda que a integração do CIC com a sociedade local (chamada comunidade) conduz ao in- 
tercâmbio entre o saber técnico-jurídico e o saber local. Este modelo aponta para o exercício de novas relações de poder.

A potencialidade dos CICs não se limita à democratização do sistema de justiça, uma vez que, contemplando os direitos sociais, alarga o conceito de direito à justiça, exigindo a democratização de outras instituições. Em algumas situações observadas na pesquisa, o CIC mostrou-se como canal de demandas da sociedade local. É o caso, por exemplo, de pessoas que obtêm vagas em escolas e hospitais por intermédio de autoridades que cobram dos estabelecimentos a garantia do direito à educação e à saúde. É o caso também de um promotor de Justiça que, em parceria com um líder comunitário, visitou as creches da região cobrando providências no sentido de adequação dos estabelecimentos aos preceitos consagrados no Estatuto da Criança e do Adolescente, fortalecendo uma reivindicação popular.

\section{DEMOCRATIZAÇÃO DO SISTEMA DE JUSTIÇA OU O CONTROLE DA PERIFERIA?}

A expectativa dos militantes da democratização em relação ao CIC deve-se às potencialidades de criação de novos arranjos institucionais que favoreçam o exercício do controle social nos marcos da democracia. Esse controle no interior do CIC, idealizado por seus criadores, exerce-se preferencialmente pela sociedade civil em relação aos agentes públicos e representantes do Estado, com estes prestando contas, cumprindo metas definidas democraticamente e sendo avaliados na eficácia de seu trabalho para a ampliação do acesso da população da periferia aos direitos de cidadania.

No entanto, a análise da microfísica dos poderes em disputa no projeto de democratização do sistema de justiça leva a concluir que são concretos os riscos de o CIC permanecer a serviço da divisão do trabalho de distribuição da justiça - lógica que caracterizou desde longa data a intervenção do Estado brasileiro nos conflitos sociais. Significa dizer que o CIC poderá excluir os canais de participação popular, convertendo-se em instrumento de cooptação de lideranças comunitárias para fins eleitorais. Poderá também reduzir-se a um pequeno e precário fórum, onde se processem os conflitos classificados como sem importância, mediados por profissionais de segunda linha, com o objetivo do controle social dos moradores da periferia.

\section{NOTAS}

1. O relatório completo da investigação está publicado: Haddad; Sinhoretto; Pietrocolla (2003).

2. No primeiro semestre de 2003, um novo equipamento foi implantado, desta vez em Francisco Morato, ampliando, assim, para cinco o número de CICs.

3. A equipe de pesquisa foi composta por seis pessoas: dois auxiliares (Carolina Di Fillipe e Frederico Normanha Ribeiro de Almeida), um supervisor de campo (Alessandra Olivato), um coordenador geral (Jacqueline Sinhoretto) e dois analistas (Eneida Gonçalves de Macedo Haddad e Luci Gati Pietrocolla). O levantamento empírico ocorreu entre os meses de novembro de 2001 e junho de 2002 , sendo que de fevereiro a maio foram realizadas visitas diárias aos equipamentos para a observação in loco.

4. O projeto foi inicialmente apresentado em 1990 ao comitê de campanha de Mário Covas, candidato pelo PSDB. Não tendo sido eleito, candidatou-se novamente em 1994. Ganhando as eleições, iniciou a implementação do CIC em 1996.

5. “'Garantia' é uma expressão do léxico jurídico que designa qualquer técnica normativa de tutela de um direito subjectivo. O significado ordinário do termo é todavia mais restrito. Por garantia entende-se, na linguagem juscivilista, uma categoria de institutos, que remontam ao direito romano, destinados a assegurar o cumprimento das obrigações e a tutela dos correspondentes direitos patrimoniais.(...) Relativamente recentes são, em contrapartida, a extensão do significado de 'garantias' e a introdução do neologismo 'garantismo' com referência às técnicas de tutela dos direitos fundamentais, entendendo-se por 'direitos fundamentais' - em oposição aos direitos patrimoniais, como a propriedade e o crédito, que são direitos singulares, adquiridos por cada um com exclusão dos outros - aqueles direitos universais, e como tal indisponíveis e inalienáveis, que são atribuídos directamente por normas jurídicas a todos, enquanto pessoas, cidadãos ou sujeitos capazes de agir: sejam esses direitos negativos, como os direitos de liberdade, a que correspondem proibições de lesão, sejam eles direitos positivos, como os direitos sociais, a que correspondem obrigações de prestação por parte dos poderes públicos. O terreno sobre o qual se produziu este alargamento do significado de 'garantias' foi o direito penal" (Ferrajoli, 2001).

6. O poder conferido ao Gabinete de Segurança Institucional nas questões de segurança pública motivou vários conflitos entre o Ministério da Justiça e o Gabinete da Presidência, sendo motivo inclusive da demissão do Ministro José Carlos Dias.

\section{REFERÊNCIAS BIBLIOGRÁFICAS}

FERRAJOLI, L. Garantias. Revista do Ministério Público. São Paulo, ano 22, n.85, p.7-24, jan./mar. 2001.

HADDAD, E.G. de M.; SINHORETTO, J.; PIETROCOLLA, L.G. Justiça e segurança na periferia de São Paulo: os centros de integração da cidadania. São Paulo: Instituto Brasileiro de Ciências Criminais, 2003.

Eneida Gonçalves de Macedo Haddad: Professora de Sociologia da FAAP, Coordenadora-Adjunta do Núcleo de Pesquisas do Instituto Brasileirode Ciências Criminais (enhaddad@uol.com.br).

JACQueline Sinhoretto: Socióloga, Bolsista de doutorado da Capes FFLCH-USP (jacsin@uol.com.br). 